\title{
Central Composite Design Approach for Optimization of Extraction and Dyeing Conditions of Marigold Colorant
}

Shaukat Ali ${ }^{*}$, Sadia Noor ${ }^{1}$, Umme Habibah Siddiqua ${ }^{1}$, Sobia Jabeen ${ }^{1}$ and Tanveer Hussain ${ }^{2}$

${ }^{1}$ Department of Chemistry, University of Agriculture, 38000, Faisalabad, Pakistan

${ }^{2}$ National Textile University, Sheikhupura Road, Manawala 37610, Faisalabad, Pakistan

\begin{abstract}
Marigold flowers are used in many Asian countries for various occasions, rituals and offerings. A considerable amount of unused marigold flowers is wasted while the used ones also pose problems in disposing off. Central composite design of experiment was used to optimize the extraction and dyeing conditions of natural dye from marigold flowers. The effect of $\mathrm{pH}$ of the extraction medium, extraction time and material to liquor ratio was investigated. It was found that $\mathrm{pH}$ and liquor ratio had statistically significant effect on dye extraction, whereas the effect of time, within the range used in this study, was not found to be significant. Optimum dye extraction was obtained in acidic $\mathrm{pH}$ of the extraction medium at lower liquor ratio. Temperature and time dyeing are the most influential factors among many other parameters including amount of salt and material-to-liquor ratio. Cotton fabric dyed with the optimized dye extract, showed very good washing and light fastness properties but poor wet crocking fastness.
\end{abstract}

Keywords: Eco-friendly natural dyes; Marigold dye extraction; RSM; Central composite design (CCD); Cotton dyeing

\section{Introduction}

Natural dyes have been in use since ancient times for coloring different substrates such as wool, cotton, silk and leather. There has also been a wide range of use of these dyes as coloring content in cosmetic products, in printing inks, watercolors and in paints [1]. A recent revival in use of natural dyes in textile industries, has gained limelight all around the world. With increasing awareness of the issues of sustainability and environment protection, the use of synthetic dyes is being considered with caution. It is believed that the use of natural dyes is a wiser and friendlier approach towards the environment as compared to the synthetic dyes. Natural dyes are known to exhibit good level of biodegradability and a high environmental compatibility [2-4].

Marigold flowers are famous for their bright yellow color range. The marigold petals contain lutein and fatty acid esters of lutein which comprise more than $90 \%$ of pigment content of plant $[5,6]$. The major coloring component (Lutein $\mathrm{C}_{40} \mathrm{H}_{56} \mathrm{O}_{2}$ ) (Figure 1) in marigold flowers belongs to the carotenoid family [7]. Lutein has many isomers but xanthophyll is present in marigold flowers in high concentrations as compared to other plants sources. These xanthophyll isomers are used as coloring agents in food products because of their yellow shade variations which range from yellow to red tones [8].

In the fields of chemistry and biology where a large number of experiments are to be conducted in order to check possible interaction among the factors, statistics play a very vital role. Response Surface Methodology (RSM) has emerged as central technique of statistical design and analyzing experiments almost all fields of research $[9,10]$. Central composite designs suit well in fitting a quadratic surface model, in addition to analyzing possible interactions among the experimental variables [11-13].

\section{Materials and Methods}

\section{Materials and equipment}

Dry marigold flowers were used as the main source of dye extraction. Lab-grade sodium hydroxide and dilute hydrochloric acid solutions were used for $\mathrm{pH}$ adjustment during dye extraction. Labgrade Glauber's salt was used to promote dye exhaustion during dyeing. All the dyeing experiments were completed on industrially prepared ready-to-dye mercerized cotton fabric using lab-scale high temperature exhaust dyeing machine. Data color SF-600 spectrophotometer with color measurement software was used for measuring color strength of the dyed fabrics. Washing, crocking and light fastness properties fabric dyed with extracts were determined by using launder-o-meter, crock meter and fado meter respectively.

\section{Selection of the experimental variables}

Three experimental variables were used for the dye extraction experiments, i.e., $\mathrm{pH}$ of the extraction medium, time of dye extraction and material to liquor ratio $(\mathrm{M}: \mathrm{L})$. The experimental variables and their levels are given in Table 1. $\mathrm{pH}$ of the extraction medium was varied from 2 to 12, the extraction time was varied from 30 to 90 minutes using conventional reflux methodology. Material-to-liquor ration (M:L) was varied from 20 to 50 , where $\mathrm{M}: \mathrm{L}$ of 20 refers to 20 parts of liquor used for 1 part of the marigold flowers.

\section{Design of experiment}

Response Surface Methodology (RSM) comprises a set of advanced design of experiment techniques that help better understanding and optimizing a response. Central Composite Design (CCD) is a popular design of experiments in RSM that is commonly used for finding the levels of input variables that optimize a response. Response surface equations in CCD can also model how changes in input variables influence a response of interest [14]. Total 20 experiments were designed and analysis of experiments was conducted using "DesignExpert 7.0" software package.

\section{Extraction of colorant from marigold}

The first step in this particular research venture was to extract the major colorant from dry marigold flowers. For this purpose, water was used as the extraction medium to ensure cost effectiveness of the reflux

*Corresponding author: Shaukat Ali, Department of Chemistry, University of Agriculture, 38000, Faisalabad, Pakistan, Tel: +923336506013; E-mail: shaukatchemist@hotmail.com

Received March 16, 2016; Accepted May 19, 2016; Published May 24, 2016

Citation: Ali S, Noor S, Siddiqua UH, Jabeen S, Hussain T (2016) Central Composite Design Approach for Optimization of Extraction and Dyeing Conditions of Marigold Colorant. Nat Prod Chem Res 4: 224. doi:10.4172/2329-6836.1000224

Copyright: ( 2016 Ali S, et al. This is an open-access article distributed under the terms of the Creative Commons Attribution License, which permits unrestricted use, distribution, and reproduction in any medium, provided the original author and source are credited. 
<smiles>CC1=CC(O)CC(C)(C)/C1=C/C=C(C)/C=C/C=C(C)/C=C/C=C(C)/C=C/C=C(C)/C=C/C1C(C)=CC(O)CC1(C)C</smiles>

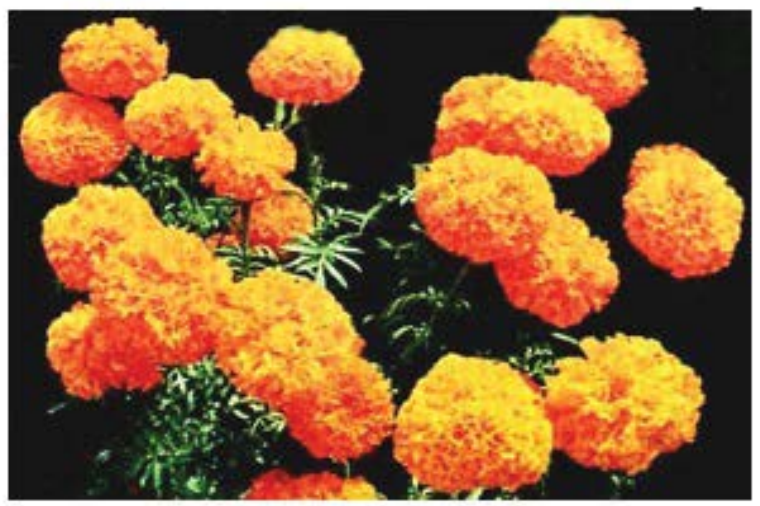

Figure 1: Structure of Lutein in Marigold and Marigold flower

\begin{tabular}{|c|c|c|c|c|c|c|}
\hline \multicolumn{2}{|c|}{ Variables } & \multicolumn{5}{|c|}{ Levels in coded and actual units } \\
\hline Symbol & Name & $-\alpha$ & -1 & 0 & +1 & $+\alpha$ \\
\hline A & $\mathrm{pH}$ & 2 & 4 & 7 & 10 & 12 \\
\hline B & Time (min.) & 30 & 42 & 60 & 78 & 90 \\
\hline C & M:L & 20 & 26 & 35 & 44 & 50 \\
\hline
\end{tabular}

Table 1: Experimental variables and their levels for extraction.

extraction process. The $\mathrm{pH}$ of the extraction medium was adjusted between 2 to 12 , according to the design of experiments by making use of dilute hydrochloric acid and sodium hydroxide.

\section{Application of dye on cotton fabric}

The extracted dye from each extraction experiment was applied on Mercerized cotton fabric samples in order to evaluate color transfer on the substrate. For this purpose a high temperature lab scale exhaust dyeing machine was used and samples were dyed at pre-optimized dyeing conditions i.e., $90^{\circ} \mathrm{C}$ for one hour. After one hour of dyeing time the dyed samples were taken out of the dye baths and cooled at room temperature. The dyed fabric was thoroughly washed and dried.

\section{Color value assessment of dyed fabric}

The color strength (K/S) values of dyed fabric samples were measured with Spectraflash - SF650 spectrophotometer by Data color International. The spectrophotometer gave the $\mathrm{K} / \mathrm{S}$ values according to the given relation $K / S=(1-R)^{2} / 2 R$, where $R$ represents sample reflectance, $\mathrm{K}$ is coefficient of absorption and $\mathrm{S}$ is the coefficient of scattering. A higher value of $\mathrm{K} / \mathrm{S}$ indicates higher color strength, as a darker sample gives lower light reflectance and higher light absorbance [15].

\section{Determination of fastness properties}

The most convenient method for evaluation of quality of dyed samples is the colorfastness properties. The variation in color values and transference of color from dyed fabric to some adjacent substrate may be due to washing, rubbing or exposure to heat or light. Textile fabric or fibers are supposed to bear washing frequently during application or usage. Hence, it becomes very important to assure the durability of colors on textile substrates [16]. The dyed cotton samples were passed through all fastness tests in accordance with ISO standard methods. Colorfastness to rubbing was determined with crockmeter according to ISO 105-X12 protocol. Colorfastness values for washing were determined using launder-o-meter according to ISO method 105$\mathrm{CO}_{2}$ while colorfastness to light was determined using Fade-o-meter according to ISO-B-02 standard method.

\section{Results}

Analysis of Variance (ANOVA): Statistical analysis of results was performed using ANOVA. The ANOVA showing the results in terms of K/S values are given in Table 2. The Model gave F-value of 165.21 and p-value $<0.0001$ implies the model is significant. There is $0.01 \%$ chance that a "Model F-Value" this large could occur due to noise. p-values less than 0.0500 indicate model terms are significant. In this case $\mathrm{A}, \mathrm{C}, \mathrm{A}^{2}$ are significant model terms. All the values greater than 0.1000 indicate the model terms are not significant. According to ANOVA results, experimental variable $\mathrm{A}$ (i.e., $\mathrm{pH}$ of the extraction medium) and $\mathrm{C}$ (i.e., $\mathrm{M}: \mathrm{L}$ ) have statistically significant effect on the color strength. The statistical significance of the term $\mathrm{A}^{2}$ implies that the effect of $\mathrm{pH}$ is not linear, as the square indicates non-linearity or curvature.

Regression coefficients for the second order equation: The purpose of Regression analysis is to investigate the model and draw a relationship between response variables and one or more experimental or predicted variables. Equation 1 gives the quantitative relationship between the experimental variables (A, B and $\mathrm{C}$ ) with color strength $(\mathrm{K} / \mathrm{S}) . \mathrm{A}$ is $\mathrm{pH}$ of the extraction medium, $\mathrm{B}$ is the extraction time in minutes and $C$ is the material to liquor ratio (M:L). Equation 1 can be used to predict the value of K/S at different levels of $A, B$ and $C$ variables. A higher magnitude (3.56) of the coefficient of variable $\mathrm{A}$ indicates that its effect on $\mathrm{K} / \mathrm{S}$ is higher as compared to variables $\mathrm{C}$ (coeff. 0.41) and B (coeff. 0.16). A -ve sign with A and C indicates their inverse relationship with the color strength $\mathrm{K} / \mathrm{S}$ whereas a +ve sign with B implies its direct relationship with the K/S [15].

\section{Equation 1:}

$\frac{K}{S}=12.49-3.56 A+0.12 B-0.41 C+0.16 A B+0.24 A C-0.062 B C-1.73 A^{2}-0.047 B^{2}-0.14 C^{2}$

The effect of $\mathrm{pH}$ and $\mathrm{M}: \mathrm{L}$ on extraction and color strength is shown in Figure 2b. Under acidic conditions, the color strength decreases with

\begin{tabular}{|c|c|c|c|c|c|c|}
\hline Source & $\begin{array}{c}\text { Sum of } \\
\text { Squares }\end{array}$ & DF & $\begin{array}{c}\text { Mean } \\
\text { Square }\end{array}$ & F Value & $\begin{array}{c}\text { p-value, } \\
\text { Prob>F }\end{array}$ & Remarks \\
\hline Model & 219.90 & 9 & 24.43 & 158.44 & $<0.0001$ & Significant \\
\hline A-pH & 173.53 & 1 & 173.53 & 1125.25 & $<0.0001$ & Significant \\
\hline B-Time & 0.19 & 1 & 0.19 & 1.22 & 0.2944 & \\
\hline C-M:L & 2.34 & 1 & 2.34 & 15.18 & 0.0030 & Significant \\
\hline AB & 0.21 & 1 & 0.21 & 1.37 & 0.2690 & \\
\hline AC & 0.45 & 1 & 0.45 & 2.93 & 0.1179 & \\
\hline BC & 0.031 & 1 & 0.031 & 0.20 & 0.6622 & \\
\hline A & 42.94 & 1 & 42.94 & 278.43 & $<0.0001$ & Significant \\
\hline B & 0.022 & 1 & 0.03 & 0.14 & 0.7142 & \\
\hline C & 0.24 & 1 & 0.24 & 1.53 & 0.2450 & \\
\hline Residual & 1.54 & 10 & 0.15 & & & \\
\hline $\begin{array}{c}\text { Lack of } \\
\text { Fit }\end{array}$ & 1.54 & 5 & 0.31 & & & \\
\hline $\begin{array}{c}\text { Pure } \\
\text { Error }\end{array}$ & 0.00 & 5 & 0.00 & & & \\
\hline Cor Total & 221.44 & 19 & & & & \\
\hline & Table 2: ANOVA for dye extraction. & & \\
\hline
\end{tabular}


increase in M:L. At higher M:L, the extraction liquor is more dilute as compared to that at lower M:L, resulting in lower color yield at higher M:L.

The optimum conditions for extraction: Using optimization constraints given in Table 3, the optimum conditions for dye extraction with maximum color strength were found to be: $\mathrm{pH}$ of the extraction medium 4; extraction time 45 minutes; and M:L 26. The color strength obtained with the optimized extract was greater than K/S14. Color fastness to washing was good with 4-5 rating of the change in color on the grey scale. Color fastness to light was also good with 5-6 rating on the blue wool scale. Dry crocking fastness was also good with a rating of 4 but wet crocking fastness was poor with 2-3 rating on the grey scale.

Optimization of dyeing conditions for marigold colorant: Marigold extract was then applied on the scoured and bleached cotton fabric and the parameters were optimized for dyeing. The dyeing parameters were; Temperature $\left({ }^{\circ} \mathrm{C}\right)$, Material-to-liquor ratio $(\mathrm{M}: \mathrm{L})$, Salt concentration $(\mathrm{g} / \mathrm{L})$ and dyeing time (minutes). The extracted colorant was applied on the fabric using High Temperature dyeing machine (Table 4).

\section{Results}

The results from ANOVA table shown significance of dyeing temperature and the time and these are the leading factors in cotton dyeing with natural colorants. The CV of the model is well controlled and the model is significant overall. The $\mathrm{K} / \mathrm{S}$ values indicated that there is temperature dependence and variations in temperature indicated that when it was $90^{\circ} \mathrm{C}$ it resulted in higher values of $\mathrm{K} / \mathrm{S}$ and hence the temperature was optimized for marigold to dye cotton fabric. Similarly it is clearly indicated from CCD interactions among parameters that when temperature is increases gradually more and more dye molecules got fixed onto fabric surface but beyond $100^{\circ} \mathrm{C}$ decomposition of molecules of dye started [17]. Time of dyeing was very well behaved at 60 minutes and salt concentration $40 \mathrm{~g} / \mathrm{L}$ was the optimum.

\section{Effect of extraction conditions on color strength}

Response surface 3D plots are depicting effects of experimental variables on the color strength value of the dyed fabric are shown in Figures 2 and 3. The three dimensional graphical representation of surface response, is a function of two independent variables while the third variable is kept at a constant level. Figure 2 represents the effect of $\mathrm{pH}$ of the extraction medium and extraction time on color strength. The effect of extraction time is not significant. It is evident that the dye extraction (as indicated by K/S) is best in acidic $\mathrm{pH}$ whereas it decreases under alkaline $\mathrm{pH}$ conditions. It is also clear that the effect of $\mathrm{pH}$ is not linear. The color strength decreases steadily by increasing $\mathrm{pH}$ from 2 to 7 , and then decreases sharply towards the alkaline $\mathrm{pH}(>7)$. It implies that the dye extraction from marigold flowers is best under acidic $\mathrm{pH}$ condition, and that the color yield is not optimum at neutral conditions and it is worse under alkaline conditions. The hydroxyl groups present in the marigold colorant make it water-soluble. At acidic $\mathrm{pH}$, there is an interaction of protonated terminal hydroxyl groups with cellulosic fabric through ion exchange reaction that helps the dye to be fixed on the fabric.

On immersing cellulosic fabric in water a negative is produced on it most probably due to Zeta Potential. The negatively charged surface of fabric then respells negatively charged species of dye. But addition of Glauber's salt compensates this situation with its positively charged ions in order to reduce/neutralize negative charge on the fabric. This mechanism facilitates the approach of dye molecules for bond formation [18].

\begin{tabular}{|c|c|c|c|c|c|c|}
\hline \multicolumn{2}{|c|}{ Variables } & \multicolumn{5}{|c|}{ Levels in coded and actual units } \\
\hline Symbol & Name & $-\alpha$ & -1 & 0 & +1 & $+\alpha$ \\
\hline A & Temperature & 70 & 80 & 90 & 100 & 110 \\
\hline B & Time & 30 & 45 & 60 & 75 & 90 \\
\hline C & M:L & 30 & 40 & 50 & 60 & 70 \\
D & Salt & 10 & 15 & 20 & 25 & 30 \\
\hline \multicolumn{7}{|c|}{ Table 3: Optimization constraints for dyeing. } \\
\end{tabular}

\begin{tabular}{|c|c|c|c|c|c|c|}
\hline Source & $\begin{array}{c}\text { Sum of } \\
\text { Squares }\end{array}$ & DF & $\begin{array}{c}\text { Mean } \\
\text { Square }\end{array}$ & F Value & $\begin{array}{c}\text { p-value, } \\
\text { Prob>F }\end{array}$ & Remarks \\
\hline Model & 46.38 & 14 & 3.31 & 2.69 & 0.0338 & significant \\
\hline A-Temperature & 14.41 & 1 & 14.41 & 11.68 & 0.0038 & \\
\hline B-Time & 9.37 & 1 & 9.37 & 7.6 & 0.0147 & \\
\hline C-M:L & 0.73 & 1 & 0.73 & 0.6 & 0.4522 & \\
\hline D-Salt & 0.48 & 1 & 0.48 & 0.39 & 0.5415 & \\
\hline AB & 0.063 & 1 & 0.063 & 0.051 & 0.825 & \\
\hline AC & 0.20 & 1 & 0.2 & 0.16 & 0.6911 & \\
\hline AD & 0.040 & 1 & 0.04 & 0.032 & 0.8595 & \\
\hline BC & 0.42 & 1 & 0.42 & 0.34 & 0.5671 & \\
\hline BD & 0.16 & 1 & 0.16 & 0.13 & 0.7238 & \\
\hline CD & 0.010 & 1 & 0.010 & $8.105 E-$ & 0.9295 & \\
\hline$A^{2}$ & 12.65 & 1 & 12.65 & 10.25 & 0.0059 & \\
\hline B & 0.58 & 1 & 0.58 & 0.47 & 0.5022 & \\
\hline$C^{2}$ & 2.82 & 1 & 2.82 & 2.29 & 0.1511 & \\
\hline$D^{2}$ & 1.49 & 1 & 1.49 & 1.21 & 0.2886 & \\
\hline Residual & 18.51 & 15 & 1.23 & & & \\
\hline Lack of Fit & 18.13 & 10 & 1.81 & 24.18 & & \\
\hline Pure Error & 0.37 & 5 & 0.075 & & & \\
\hline Cor Total & 64.89 & 29 & & & & \\
\hline & Tab & & & & & \\
\hline
\end{tabular}

Table 4: ANOVA for dye application.

There is a relation between the dye structure and cotton fabric which is fairly affected by changing the $\mathrm{pH}$ of dye bath. Since the lutein colorant present in marigold flowers has slight negative charge on acidic $\mathrm{pH}$ (4) which could help in forming H-bond with hydroxyl groups of cellulosic fabric. But when $\mathrm{pH}$ is raised further, there caused repulsion between dye and cotton fabric due to more anionic character. Higher $\mathrm{pH}$ decrease dyeability of fabric might be due to resonance contributing structures of lutein in marigold [19].

\section{Conclusion}

Natural dyes depend on a number of factors and $\mathrm{pH}$ of the extraction medium was found to be the most influential factor in the extraction of natural dye from marigold flowers. The next most important factor was the material to liquor ratio whereas the effect of extraction time was not found to be significant, within the range of time investigated in this study. The optimum dye extraction took place at $4 \mathrm{pH}, 1: 26$ material-to-liquor ratio in 45 minutes time of extraction. The effect of $\mathrm{pH}$ was found to be non-linear on the color yield, which decreased steadily by increasing $\mathrm{pH}$ from 4 to 7 but then sharply from pH 7 to 10. Cotton fabric dyed with the optimized dye extract showed good washing fastness (4-5 rating on 1-5 scale), good light fastness (5-6 rating on 1-8 scale), fairly good dry crocking fastness (4 rating on 1-5 

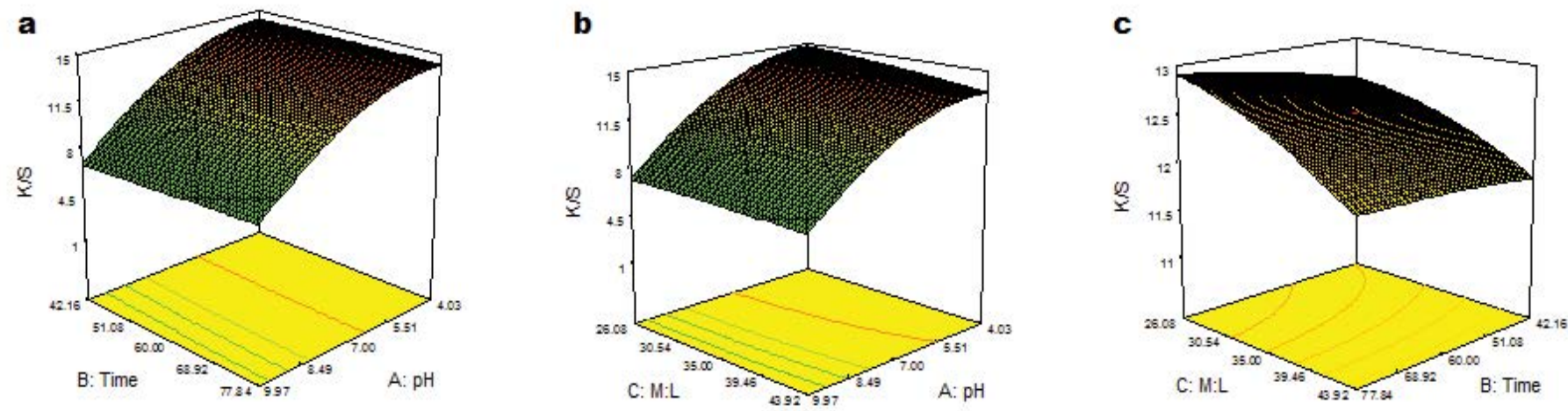

Figure 2: Effect of extraction parameters a) $\mathrm{pH}$ and time on color strength (K/S) at M:L $35 \mathrm{~mL} ; \mathrm{b}) \mathrm{pH}$ and $\mathrm{M}: \mathrm{L}$ on color strength (K/S) at $60 \mathrm{~min}$; c) Time and M:L at $\mathrm{pH} 4$.

a
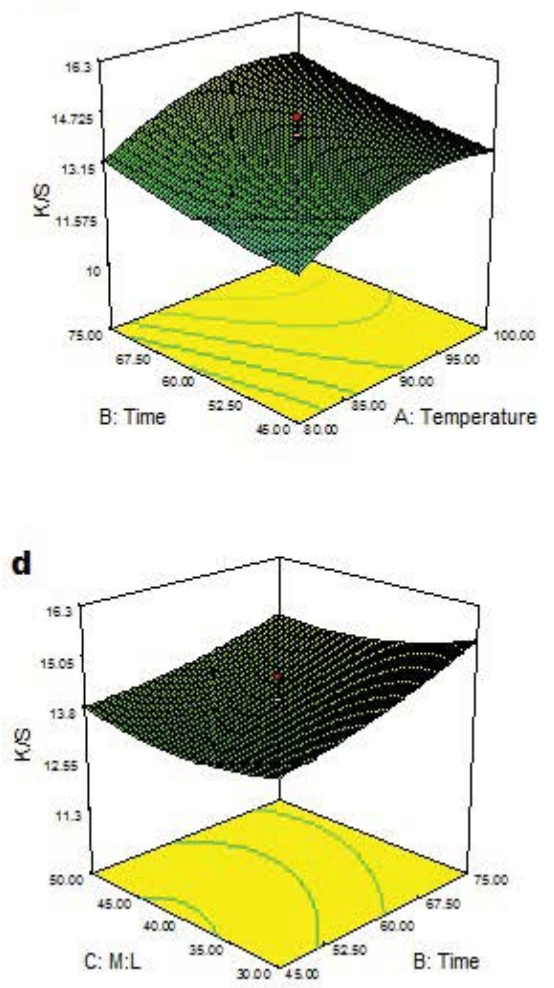

b

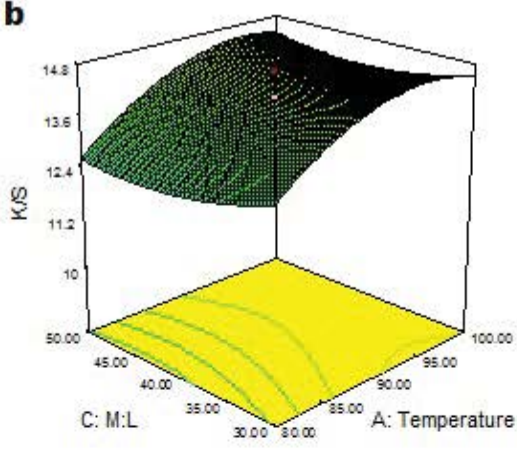

e

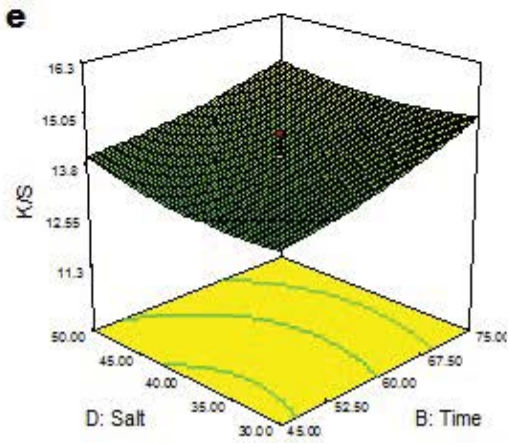

c

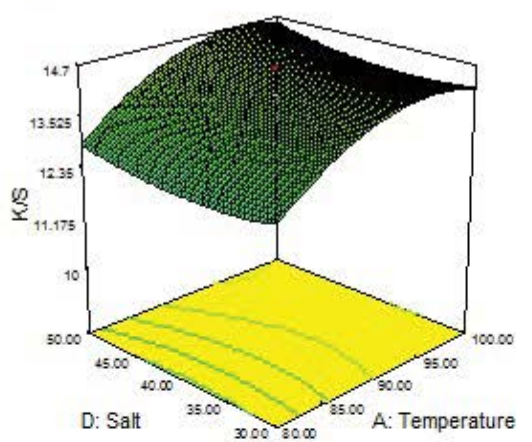

$\mathbf{f}$

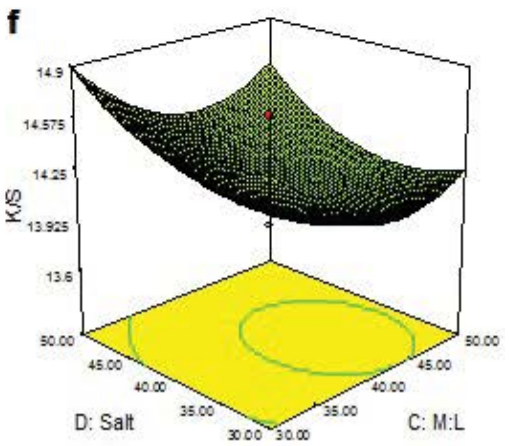

Figure 3: Effects of parameters on color strength (K/S) a) Temperature and dyeing time; b) Temperature and M:L; c) Temperature and Salt (g/L); d) M:L and dyeing time; e) Salt and Dyeing time; f) Salt and M:L.

scale) but poor wet crocking fastness (2-3 rating on 1-5 scale). Dyeing conditions were also optimized in terms of dyeing temperature $\left(90^{\circ} \mathrm{C}\right)$, dyeing time (60 minutes), salt concentration $(40 \mathrm{~g} / \mathrm{L})$ and materialto-liquor ratio $(40 \mathrm{~mL})$. Further work is required to improve the wet crocking fastness of marigold dye on cotton fabric.

\section{Acknowledgements}

This experimental work was completed in the Department of Chemistry, University of Agriculture, Faisalabad, Pakistan.

\section{References}

1. Cristea D, Vilarem $G$ (2006) Improving light fastness of natural dyes on cotton yarn. Dyes and Pigments 70: 238-245.

2. Kamel MM, El-Shishtawy RM, Yussef BM, Mashaly H (2005) Ultrasonic assisted dyeing: III. Dyeing of wool with lac as a natural dye. Dyes and Pigments 65 103-110.

3. Ali S, Hussain T, Nawaz R (2009) Optimization of alkaline extraction of natura dye from Henna leaves and it's dyeing on cotton by exhaust method. Journal of Cleaner Production 17: 61-66. 
Citation: Ali S, Noor S, Siddiqua UH, Jabeen S, Hussain T (2016) Central Composite Design Approach for Optimization of Extraction and Dyeing Conditions of Marigold Colorant. Nat Prod Chem Res 4: 224. doi:10.4172/2329-6836.1000224

4. Sivakumar V, Vijaeeswarr J, Anna JL (2011) Effective natural dye extraction from different plant materials using ultrasound. Industrial Crops and Product 33: 116-122.

5. Quackenbush FW, Miller SL (1972) Composition and analysis of the carotenoids in marigold petals. J Assoc Off Anal Chem 55: 617-621.

6. Piccaglia R, Mauro M, Silvia G (1998) Lutein and lutein ester content in differen types of Tagetes patula and T. erecta. Industrial Crops and Products 8: 45-51.

7. Pant S (1998) Oak bark, Abican marigold and Kerala flowers; Sources of dyes for dyeing wool. Textile Dyer and Printer 31: 11-15.

8. Verghese $J$ (1998) Focus on xanthophylls from Tagetes Erecta $L$ the giant natural complex-I. Indian Spices 33: 8-13.

9. Montgomery DC (2005) Design and Analysis of Experiments: Response surface method and designs. New Jersey, John Wiley and Sons, Inc.

10. Sun Q, Xiao W, Xi D, Shi J, Yan X, et al. (2010) Statistical optimization of biohydrogen production from sucrose by a co-culture of Clostridium acidisoli and Rhodobacter sphaeroides. International Journal of Hydrogen Energy 35: 4076-4084.

11. Branchu S, Forbes RT, York P, Nyqvist H (1999) A central composite design to investigate the thermal stabilization of lysozyme. Pharm Res 16: 702-708.
12. Jothi D (2008) Extraction of natural dyes from African marigold flower Tagetes ereectal for textile coloration. Autex Research Journal 8: 49-53.

13. Guinot P, Gargadennec A, Valette G, Fruchier A, Andary C (2008) Primary flavonoids in marigold dye: extraction, structure and involvement in the dyeing process. Phytochem Anal 19: 46-51.

14. Nasirizadeh N, Dehghanizadeh V, Yazdanshenas ME, Moghadam MR, Karim A (2012) Optimization of wool dyeing with rutin as natural dye by central composite design method. Industrial Crops and Products 40: 361-366.

15. Ibrahim NA, El-Gamal AR, Gouda M, Mahrous F (2010) A new approach for natural dyeing and functional finishing of cotton cellulose. Carbohydrate Polymers 824: 1205-1211.

16. Giri DVR, Venugopal J, Sudha S, Deepika G, Ramakrishna S (2009) Dyeing and antimicrobial characteristics of chitosan treated wool fabrics with henna dye. Carbohydrate Polymers 75: 646-650.

17. Sinha K, Saha PD, Datta S (2012) Response surface optimization and artificia neural network modeling of microwave assisted natural dye extraction from pomegranate rind. Industrial Crops and Product 37: 408-414.

18. Shenhnai VA (1997) Technology of textile processing 2: 159-193.

19. Montazer M, Parvinzadeh M (2004) Colorimetric properties of wool dyed with natural dyes after treatment with ammonia. Coloration Technology 1204: 161-166. 